\title{
Across-Channel Distribution of the Mean and Tidal Flows in the Khuran Channel, Persian Gulf, Iran
}

\author{
Maziar Khosravi $^{*}$, Seyed Mostafa Siadatmousavi ${ }^{2}$, Vahid Chegini ${ }^{1}$, Ross Vennell ${ }^{3}$ \\ ${ }^{1}$ Iranian National Institute for Oceanography and Atmospheric Science, Tehran, Iran \\ ${ }^{2}$ School of Civil Engineering, Iran University of Science and Technology, Tehran, Iran \\ ${ }^{3}$ Department of Marine Science, University of Otago, Dunedin, New Zealand \\ Corresponding author: Maziar Khosravi (mazyar.khosravi@inio.ac.ir)
}

\section{ARTICLE INFO}

Article History:

Received: 22 Nov. 2017

Accepted: 30 Apr. 2018

Keywords:

Persian Gulf

Khuran Channel

Tidal Currents

ADCP measurements

\begin{abstract}
The Khuran Channel, Southern Iran $\left(26^{\circ} 45^{\prime} \mathrm{N}\right)$, is a topographically complex channel which is open at both ends. Owning to its particular geometry, this narrow channel is subjected to strong tidal currents. Across-channel distribution of the mean and tidal flows were obtained over a semidiurnal tidal cycle in the Khuran Channel where the highest tidal velocity in the third day of the secondary spring tide exceeded $140 \mathrm{~cm} / \mathrm{s}$. Velocity profiles were obtained using a $614.4 \mathrm{kHz}$ Teledyne RDI Workhorse Broadband ADCP over 13 repetitions of a cross-channel transect. The $3.1 \mathrm{~km}$ long transect ran north/south across the channel. The $\mathrm{M}_{2}$ frequencywas separated from the observed current using sinusoidal form functions and the least square regression analysis. Contrary to the previous study in this channel, the mean inflow observed in the deep parts of the channel and mean outflow occurs over the shallow slopes, with the maximum magnitudes $(15-20 \mathrm{~cm} / \mathrm{s})$ near the surface in the north side. The maximum lateral shear and convergence were found over slopes located between the middle and the north side of the channel.
\end{abstract}

\section{Introduction}

The Straits of Hormuz is a key waterway which connects the Persian Gulf to the north part of the Indian Ocean. The Khuran Channel (KCh) in the Strait of Hormuz located at $26^{\circ} 45^{\prime} \mathrm{N}$ and $55^{\circ} 40^{\prime} \mathrm{E}$ with $\sim 110$ $\mathrm{km}$ length and the minimum width of $3.2 \mathrm{~km}$ at the port of Pol (Figure 1).The $\mathrm{KCh}$ is a topographically complex channel which is open at both ends. Owning to its particular geometry, this narrow channel is subjected to strong tidal currents. According to the bathymetry data provided by the National Cartographic Center of Iran, the maximum depth in this shallow channel reaches to $42 \mathrm{~m}$ in a trench at its narrowest section. Results of moored current meters measurements by Azizpour and Siadatmousavi [1]in the Strait of Hormuz showed that tidal currents have the main contributions in the observed current throughout the water column in this area. The tides in the Strait of Hormuz and consequently in the $\mathrm{KCh}$ are co-oscillate those in the northern Indian Ocean[2].The tidal current in the $\mathrm{KCh}$ is directed westward during flood and eastward during ebb. Previous observation in the $\mathrm{KCh}$ by Zaker, Ghaffari [3]showed that currents were dominated by tidal forcing with mixed semi-diurnal characteristics such that the $\mathbf{M}_{2}$ component was the most important tidal signal. Also it was concluded that the water column over most of the KChwas almost vertically homogenous. Hence, tides in this shallow channel were likely almost barotropic.

In narrow channels like the $\mathrm{KCh}$, the structure of across-channel flow is often highly variable, with changes occurring on spatial scales on the order of hundreds of meters and temporal scales of minutes. Spatial and temporal variations of the cross-channel flow are highly considerable due to the interaction among lateral bathymetric changes, tidally-driven currents, gravitational circulation, and wind-driven currents[4]. There are several studies which emphasize the importance of across-channel flow in estuarine environments and channel systems [e.g. 5, 6-14]. 


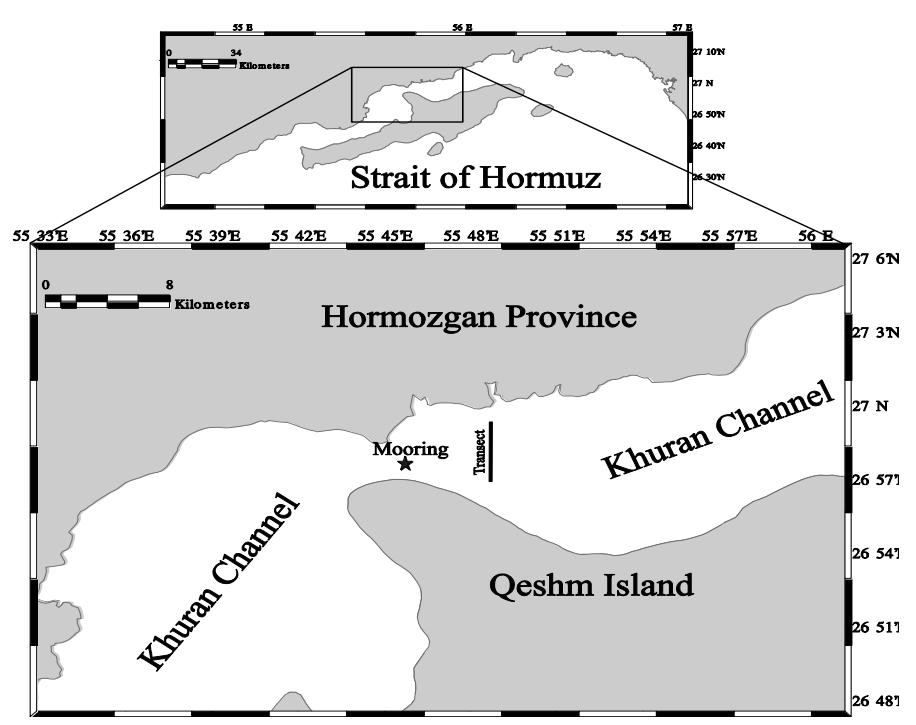

Fig. 1 Map of study area. The across-channel transect in this study was located at the right side of the narrowest section of $\mathrm{KCh}$. The mooring location is shown at the narrowest section.

Direct observations in the $\mathrm{KCh}$ are both terribly important and difficult to accomplish. The high volume of ship traffic combined with extensive fishing activities make this region very risky for moored observations. In the light of recent developments, the broadband ADCP is progressed in order to make more accurate measurements of current profiles compared with those of narrowband systems. Taking advantage of its higher measurement accuracy, a higher spatial resolution can be obtained by those instruments. Hence, combining higher measurement accuracy with the convenient positioning system, it is possible to measure the spatial variations in the flow on the small spatial scales. Thus, a vessel mounted ADCP survey provides a direct and accurate estimate of the system dynamics from the data, instead of concluding them from fixed point current observations assuming some theoretical form Old and Vennell [15].

Various pollutants released in the $\mathrm{KCh}$ which are caused by the urban and industrial development in the Qeshm Island as well as ports along this channel. Knowledge about the mean flow and tidal flow in the coastal marine environments are essential to predict the fate of the pollutants, and consequently for environmental studies. The vessel mounted-ADCP measurements presented in this study have provided the first description of the spatial variability of the mean and tidal flows along a cross-channel transect within the $\mathrm{KCh}$ at the secondary spring tide.

\section{Materials and Methods}

A vessel mounted $614.4 \mathrm{kHz}$ Teledyne RDI Workhorse Broadband ADCP and a Garmin GPSMAP 521s interfaced to a laptop computer were used to obtain detailed profiles of the mean and tidal flows in the $\mathrm{KCh}$ over 13 repetitions of a cross-channel transect during one semidiurnal tidal cycle, on 10 October 2014, the third day of secondary spring tide in the area. The 3.1 $\mathrm{km}$ long transect which located on longitudes of $55.787^{\circ} \mathrm{E}$, ran north/south across the channel(in the sense used by Cáceres, Valle-Levinson [8]). Observation of the current along the mentioned transect is part of a more detailed study on observation of tidal currents in the KCh. The ADCP was deployed in downward position along the starboard side of a small vessel $\sim 3 \mathrm{~m}$ long, which was moved at the maximum speed of $\sim 2.5 \mathrm{~m} / \mathrm{s}$. The depth of the ADCP transducers was set to be $\sim 0.83 \mathrm{~m}$ below the water surface. Considering that the blanking distance for a Workhorse $600 \mathrm{kHz}$ is equal to $1 \mathrm{~m}$, the first bin was $\sim 1.83 \mathrm{~m}$ below the water surface. Additionally, the aforementioned ADCP was capable of bottom tracking and the vertical bin height has been set to $1 \mathrm{~m}$. Velocity profiles were averaged over ensembles for both the velocity and the bottom tracking data every 40 s.

The KCh is almost along the east-west axis; however, the direction of the strongest shear variability of tidal currents and of the weakest across-channel tidal flows was -4 degrees. Thus the data were rotated 4 degrees clockwise to the east-west(x-direction, ucomponent)and north-south(y-direction, $v$ component).The ADCP's compass was calibrated, as explained in Joyce [16]. After rotation of the axes, the instantaneous data were adjusted into uniform grids of $1 \mathrm{~m}$ depth and $100 \mathrm{~m}$ length aligned with tracks and the harmonic analysis was performed independently on the time series generated at each grid point. The tidal frequencies of $\mathrm{M}_{2}, \mathrm{M}_{4}$ and $\mathrm{M}_{6}$ were separated from the observed current using sinusoidal least squares regression analysis (Eq. 1):

$$
u=u_{0}+\sum a_{n} \cos \left(\omega_{n}-\Phi_{n}\right)
$$

where $u$ is representative of the component of horizontal velocity, $u_{0}$ the mean value of $u$ over a tidal cycle, and for the $n$-th constituent $a_{n}$ is the amplitude, $\omega_{n}$ the angular frequency, $\Phi_{n}$ phase angle, and t is time[17]. Tidal flows could be influenced by wind and sea condition; however, the current survey was performed during calm weather condition and no significant wave height. The root mean square $(\mathrm{rms})$ errors of the least-square fits were between $\sim 0.1 \mathrm{~m} / \mathrm{s}$ and $0.4 \mathrm{~m} / \mathrm{s}$ for the current transect and the mean error was less than $0.1 \mathrm{~m} / \mathrm{s}$.

Furthermore, the principal component analysis [18]was employed to the moored current meter data from the observation of Zaker et. al [3]to calculate the alongchannel and cross-channel components of current velocities. Then, tidal and residual current were separated from the observed current using the MATLAB toolbox t_tide [19]. In addition, spectral analysis [20] of moored current data is also presented.

\section{Results and Discussion}

In this part, the time series of along-channel and crosschannel current, tidal and residual current from current meter measurements of[3]are reconstructed. Spectra of 
current velocities at the moored current meter location are presented. Also the across-channel distribution of the mean and tidal flows in the $\mathrm{KCh}$, for the period of observation is designated. Finite difference method is used to discretize the gradients in time and space. The temporal average of gradients over semidiurnal tidal cycle was calculated, afterward.

\subsection{Moored Current Meter Measurements}

The mooring (Fig 1)was deployed within the narrowest section for a period of 34days in 5 meter below the water surface in summer 2005[3].

\subsubsection{Observed Current, Tidal and Residual Currents}

Fig. 2 shows the reconstructed components of current at the location of moored current meter observation of [3]. The panel composed of observed current, tidal current, and residual current. The residual current is the difference between the observed current and tidal current[21]. As appeared from this panel, residual current with maximum magnitude of $23.1 \mathrm{~cm} / \mathrm{s}$ had small contribution to the observed flow. Tidal current with the maximum magnitude of $\sim 111 \mathrm{~cm} / \mathrm{s}$ was the main component of the observed current. The highest magnitude of the observed current was $120 \mathrm{~cm} / \mathrm{s}$. As an evidence of tidal asymmetry, during spring tide, the flood velocity was larger than ebb one (see alongchannel observed current inFig.2) which leads to the along-channel mean flow over a tidal cycle.

\subsubsection{Spectral Analysis}

Fig. 3 shows result of the spectral analysis at the moored current meter location at 5 meter depth below the water surface. It demonstrates that diurnal $\left(\mathrm{K}_{1}, \mathrm{O}_{1}\right)$ and semidiurnal $\left(\mathrm{M}_{2}, \mathrm{~S}_{2}\right)$ tidal constitutes were the most energetic signals in this channel. The $\mathbf{M}_{2}$ tidal constituent was almost one order of magnitude more energetic than the $\mathrm{K}_{1}$ tidal constituent. The spectrum is roughly symmetric on both positive and negative frequencies; which means the flow mostly move in the along-channel direction.

Inertial oscillation was appeared as a peak of negative frequency with period of $\sim 26.4 \mathrm{~h}$. Furthermore, relative energetic peaks were seen at quarter-diurnal tide (e.g., $\mathrm{M}_{4}$ ) and third-diurnal tide (e.g., $\mathrm{M}_{3}$ ). Overtides are harmonic motions in which their frequencies are higher than semidiurnal tides. Parker [22] explained that the source of nonlinear overtide $\mathrm{M}_{4}$ usually arise from nonlinearities in continuity equation, advection terms in momentum equations and effects of the bottom friction.
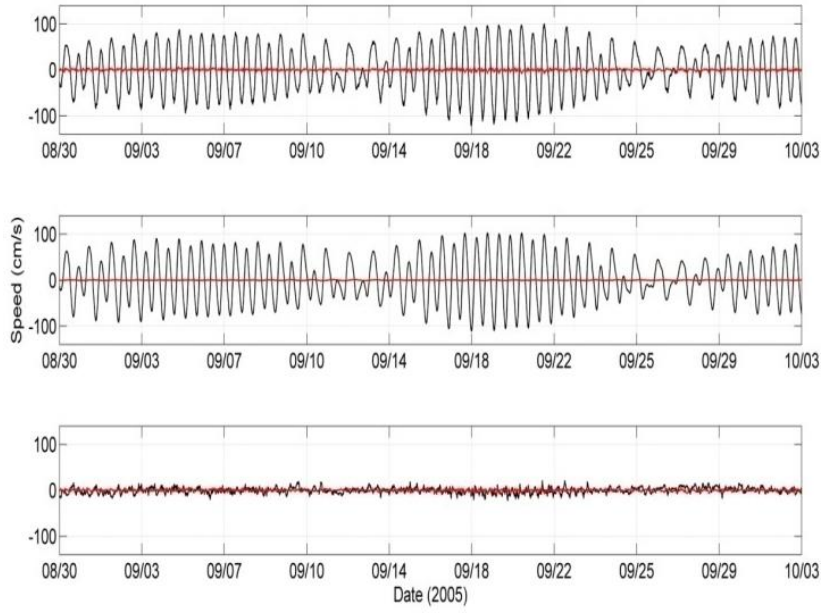

Fig. 2Time series of along-channel (black line) and crosschannel (red line) current at the location of mooring; upper, middle and lower plot are observed current, tidal current and residual current, respectively.

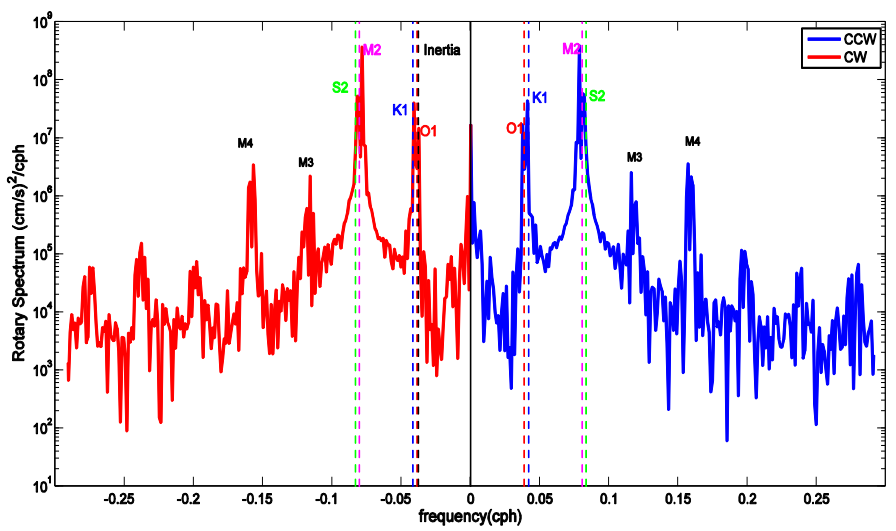

Fig. 3 Rotary spectra for the current at mooring site which was located at 5 meter below the water surface

\subsection{Vessel Mounted-ADCP Surveys \\ 3.2.1. Mean Flow}

Fig. 4 shows the main characteristic of across-channel distribution of the u-mean flow over the period of observations. Study of [3] concluded that there is a westward residual current in the $\mathrm{KCh}$ and hence any pollutant in the industrial eastern part of this channel would move westward. Contrary to their results, the vessel mounted ADCP measurements of the current study indicated that the u-mean flow was influenced significantly by bathymetry as inflows (negative values) observed in the deep part of the channel and outflows (positive values) over the shallow slopes, more evident in the north side of the channel. As a result, the pollutants would move westward in the deep part of the channel and eastward motion of pollutant will occur over shallow slopes.

The mean flow wasresembled to that inferred from theoretical results in a weakly stratified coastal plain estuary in Delaware Bay[5]. The same results also observed at Yeomha Channel, Gyeonggi bay, South Korea[14]. The along-channel mean flow showed the greatest magnitudes $(15-20 \mathrm{~cm} / \mathrm{s})$ near the surface in the northern side. The magnitude of the u-mean flow 
was in a fair agreement to those residual current observed at moored current meter location of [3], with the maximum magnitude of $23.1 \mathrm{~cm} / \mathrm{s}$ in the secondary spring tide. In the deep part of the channel, outflows occurred over the entire water column. The alongchannel mean $\mathrm{u}$ flow exhibited a mean absolute magnitude of $7.9 \mathrm{~cm} / \mathrm{s}$ in the section.

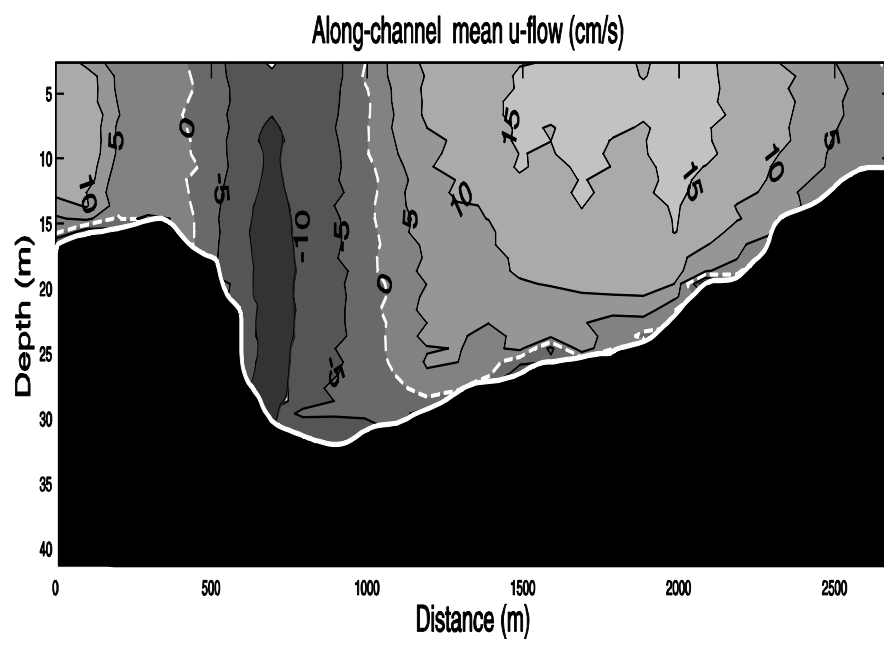

Fig. 4 Across-channel distribution of the along-channel mean flow (looking toward the ocean, the left side of the plot is South and the right side is North). Positive values (light colors) indicate currents to the north and negatives (dark colors) to the south.

The mean outflows were dominated by strong lateral shears $\left(\frac{\partial u}{\partial y}\right)$ in the north side.The mean lateral shears revealed high positive and negative shears extended over the entire water column in the shoal at the north side. These significant gradients specify the strong east-west $u$ flow. The maximum negative shear occurred over the north shoulder of the channel. The mean lateral shears in the $\mathrm{KCh}$ over the shoals were similar to those findings of Valle-Levinson and Atkinson [4]in the Thimble Shoal channel, lower Chesapeake Bay. The values of the shears ranged from $-15 \times 10^{-4}$ to $10 \times 10^{-4} \mathrm{~S}^{-1}$, with sectional mean of $\sim 8.3 \times 10^{-4} \mathrm{~S}^{-1}$. Variances estimated for all shears were close to $2.1 \times 10^{-7} \mathrm{~S}^{-1}$. The magnitude of these gradients is up to $10^{-4}$.In other words, they are one order of magnitude lower than those reported for example in the Chacao Channel, Southern Chile[8]. These magnitude were in the same order of magnitude to those inferred in the Chesapeake Bay [4].

In the case of across-channel mean v-flow (Fig. 5), it showed dominance of negative values (flow to the south) near the bottom. It also featured two changes of direction near the surface from south to north in small distance of $3.1 \mathrm{~km}$ and hence determining regions of convergence and divergence which is more evident in the upper $15 \mathrm{~m}$, in agreement with the distribution of the $\left(\frac{\partial v}{\partial y}\right)($ Fig. 6).The mean v-flow showed a mean absolute magnitude of $3.9 \mathrm{~cm} / \mathrm{sin}$ the section.

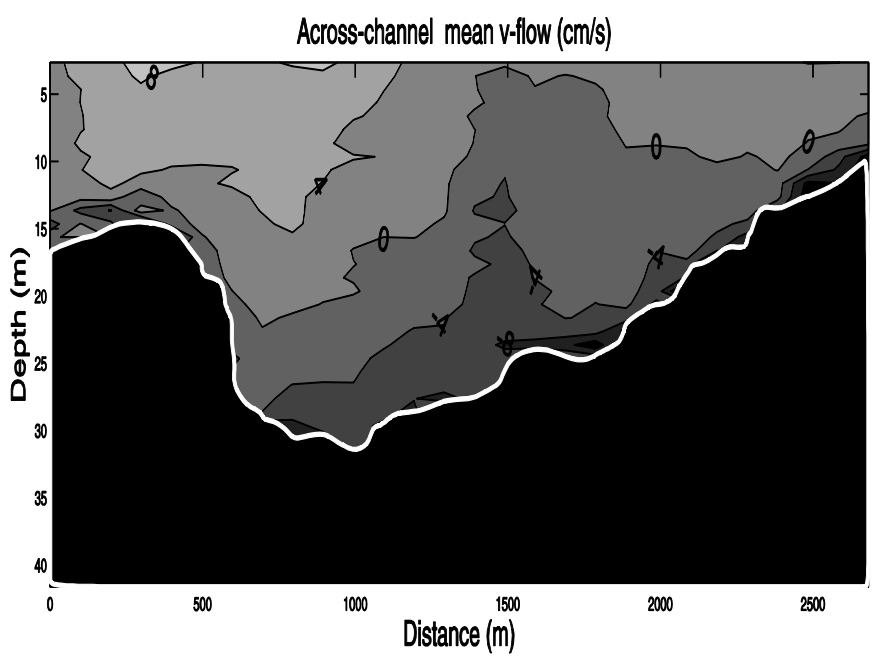

Fig. 5 Across-channel component of the mean v-flow. Positive values (light colors) indicate currents to the north and negatives (dark colors) to the south.

The across channel distribution of $\left(\frac{\partial v}{\partial y}\right)$ over the water column also showed zonation, probably related to bathymetry (Fig.6). The location of the greatest convergence (negative contours and dark tones) and divergence (positive contours and light tones) occurred over the mid to the north side of the channel. It occurred almost in the area of the strongest mean lateral shears. These strong divergences are attributed to large lateral shears as also concluded by Valle-Levinson, Reyes [23].The values for $\left(\frac{\partial v}{\partial y}\right)$ were almost of the same order of magnitude as $\left(\frac{\partial u}{\partial y}\right)$, but smaller, and ranging from $-4 \times 10^{-4}$ to $2 \times 10^{-4} \mathrm{~s}^{-1}$. Variances estimated for the across-channel tidally-averaged divergence was $4.4 \times 10^{-8} \mathrm{~s}^{-1}$. Again, the magnitude of these gradients is up to $10^{-4}$; and then, they are one order of magnitude lower than those calculated in the Chacao Channel[8]. These magnitude were in the same order of magnitude to those reported in the Chesapeake Bay [4].

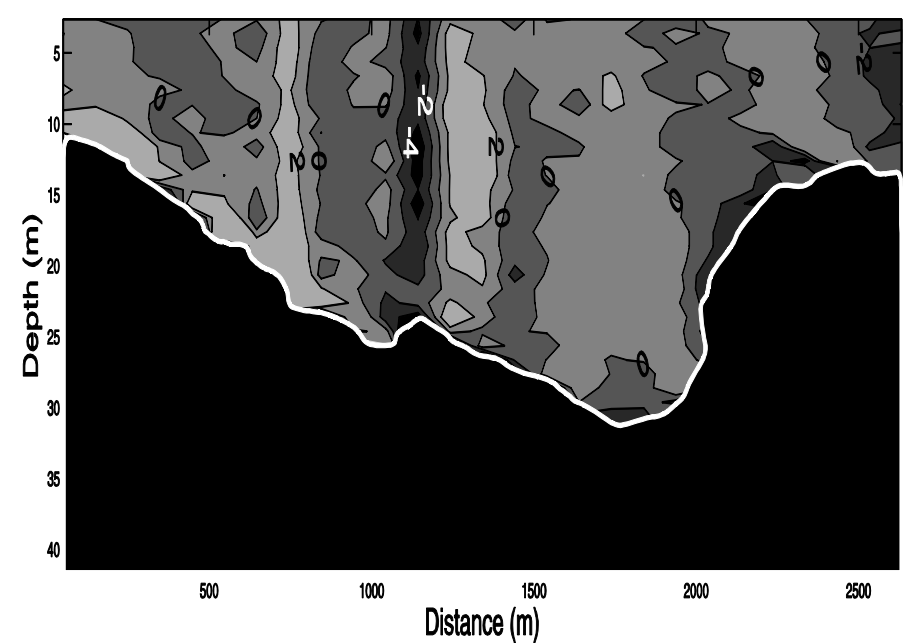

Fig.6 Contours of the mean divergence $\left(\left(\frac{\partial v}{\partial y}\right) \times 10^{-4} S^{-1}\right)$ of the across-channel flow. 


\subsubsection{Tidal flow}

The across-channel distribution of the semidiurnal tidal current amplitudes is shown in Fig. 7.The maximum amplitudeexceeded $140 \mathrm{~cm} /$ sand occurred near the surface. Clearly, the tidal velocity contours followed the bathymetry which emphasize on the relative domination of frictional force in dynamical terms. In other words, the semidiurnal tidal current amplitudes reduced in the deep part of water column and the smallest tidal amplitude was observed near the bottom which indicated the importance of the bottom friction[4, 7, 8, 22, 24-27].This was also evident in relative energetic peak at quarter-diurnal tide (e.g., $\mathrm{M}_{4}$ ) in the rotary spectra (Fig. 3) that implies the effect of bottom friction through the nonlinear overtide $\mathrm{M}_{4}$ (not plotted here). The results obtained here were consistent with those observed by Valle-Levinson and Atkinson [4] and Valle-Levinson and Lwiza [6]. Tidal current with the highest magnitude of $\sim 111 \mathrm{~cm} / \mathrm{s}$ at the mooring location in the spring tide was comparable to those across-channel distributions of the semidiurnal tidal current amplitudes that ranged $100-150 \mathrm{~cm} / \mathrm{s}$.

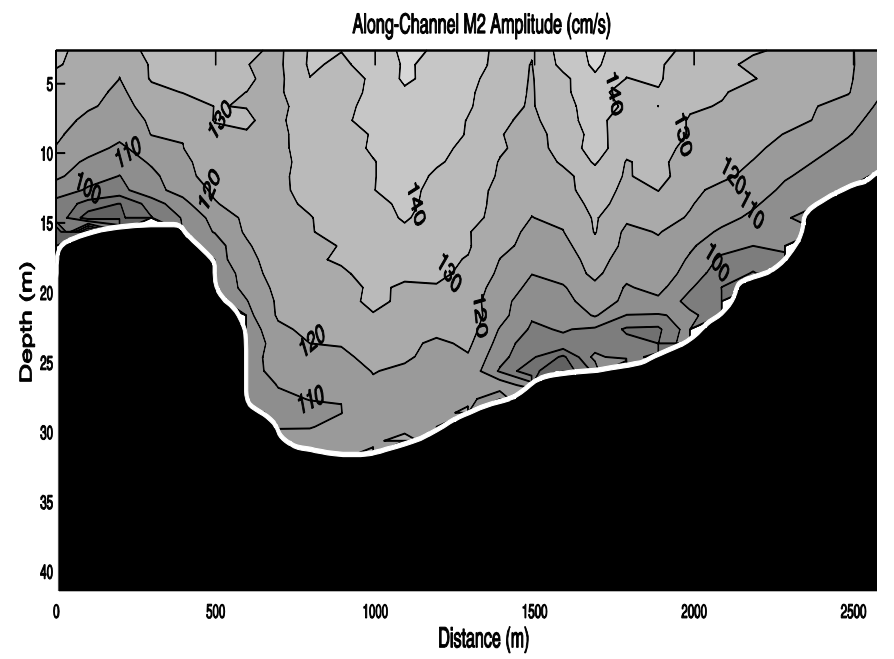

Fig.7 Across-channel tidal amplitude distributions for the M2 constituent

\section{Conclusions}

Due to the relatively large maritime traffic volume which make moored observation so risky in the $\mathrm{KCh}$, this study through vessel-mounted ADCP surveys gives the first detailed description of mean and tidal current on high spatial and temporal resolution in this channel. The spectral characteristics of the moored current meter in the $\mathrm{KCh}$ confirmed that the tidal and inertial oscillations were the main components of current in this channel. Diurnal and semidiurnal tidal constitutes showed the largest energy in which $\mathrm{M}_{2}$ tidal constituent was almost one order of magnitude more energetic than $K_{1}$ tidal constituent (see figure. 3).

The study of flow in this topographically complex channel revealed that the mean flow is flood-dominated over the slope in shallow areas, mostly in the north side of the channel. It is also ebb-dominated through the water column in the deep part of the channel, which resembled to that concluded from theoretical results by Wong [5] and also observed by Lee and Woo[14].Contrary to the results by [3], the current study indicated that the pollutants would move westward in the deep part of the channel and also eastward motion of pollutant will occur over shallow slopes. The highest mean flow in the $\mathrm{KCh}(15-20 \mathrm{~cm} / \mathrm{s})$ was near the surface in the northern side. The current speed, horizontal velocity shear and convergence were enhanced over slopes of the mid to the northern side of the channel. The maximum amplitude of semidiurnal tidal current exceeded to $140 \mathrm{~cm} / \mathrm{s}$ which occurred near the surface and gradually reduced with depth. The semidiurnal tidal current contours followed the bathymetry which indicates the predominant of frictional forces in the dynamical terms. Particularly, the minimum tidal amplitude was measured near the bed, again due to effects of the bottom friction. These results were in a fair agreement with the previous studies $[4,6,8,23]$

\section{References}

1. Azizpour, J., S.M. Siadatmousavi, and V. Chegini, (2016), Measurement of tidal and residual currents in the Strait of Hormuz. Estuarine, Coastal and Shelf Science. Vol.178(2),p.101-109.

2. Reynolds, R.M., (1993), Physical oceanography of the Gulf, Strait of Hormuz, and the Gulf of Oman-Results from the Mt Mitchell expedition. Marine Pollution Bulletin, Vol.(27): p. 3559.

3. Zaker, N., et al., (2011), Dynamics of the Currents in the Strait of Khuran in the Persian Gulf. Journal of Shipping and Ocean Engineering, Vol.1(2).

4. Valle-Levinson, A. and L.P. Atkinson, (1999), Spatial gradients in the flow over an estuarine channel. Estuaries, Vol.(22)2: p. 179-193.

5. Wong, K.C., (1994), On the nature of transverse variability in a coastal plain estuary. Journal of Geophysical Research: Oceans, Vol.99(C7): p. 14209-14222.

6. Valle-Levinson, A. and K.M. Lwiza, (1995), The effects of channels and shoals on exchange between the Chesapeake Bay and the adjacent ocean. Journal of Geophysical Research: Oceans, Vol.100(C9): p. 18551-18563.

7. Valle-Levinson, A., K.C. Wong, and K.M. Lwiza, (2000), Fortnightly variability in the transverse dynamics of a coastal plain estuary. Journal of Geophysical Research: Oceans, Vol.105(C2): p. 34133424.

8. Cáceres, M., A. Valle-Levinson, and L. Atkinson, (2003), Observations of cross-channel structure of flow in an energetic tidal channel. Journal of Geophysical Research: Oceans, Vol.108(C4).

9. Doyle, B.E. and R.E. Wilson, (1978), Lateral dynamic balance in the Sandy Hook to Rockaway Point 
transect. Estuarine and Coastal Marine Science, Vol.6(2): p. 165-174.

10. Chant, R.J. and R.E. Wilson, (1997), Secondary circulation in a highly stratified estuary. Journal of Geophysical Research: Oceans, Vol.102(C10): p. 23207-23215.

11. Hughes, F. and M. Rattray, (1980), Salt flux and mixing in the Columbia River Estuary. Estuarine and Coastal Marine Science, Vol.10(5): p. 479-493.

12. Dyer, K., (1997), Estuaries: a physical introductionWiley. New York.

13. Cameron, W., (1951), On the transverse forces in a British Columbia inlet. Transactions of the Royal Society of Canada, Vol.(45): p. 1-9.

14. Lee, D. and S. Woo, (2011), Characteristics of cross-channel momentum balance at Yeomha Channel, Gyeonggi bay, South Korea. JOURNAL OF COASTAL RESEARCH: p. 1515-1519.

15. Old, C. and R. Vennell, (2001), Acoustic Doppler current profiler measurements of the velocity field of an ebb tidal jet. Journal of Geophysical Research: Oceans, Vol.106(C4): p. 7037-7049.

16. Joyce, T.M., (1989), On in situ "calibration" of shipboard ADCPs. Journal of Atmospheric and Oceanic Technology. Vol.6(1): p. 169-172.

17. Lwiza, K., D. Bowers, and J. Simpson, (1991), Residual and tidal flow at a tidal mixing front in the North Sea. Continental Shelf Research. Vol.11(11): p. 1379-1395.

18. Preisendorfer, R.W. and C.D. Mobley, (1988), Principal component analysis in meteorology and oceanography. Vol. 425: Elsevier Amsterdam.
19. Pawlowicz, R., B. Beardsley, and S. Lentz, (2002), Classical tidal harmonic analysis including error estimates in MATLAB using T_TIDE. Computers \& Geosciences. Vol.28(8): p. 929-937.

20. Hayashi, Y., (1979), Space-time spectral analysis of rotary vector series. Journal of the atmospheric sciences. Vol.36(5): p. 757-766.

21. Boon, J.D., (2013), Secrets of the tide: tide and tidal current analysis and predictions, storm surges and sea level trends: Elsevier.

22. Parker, B.B., (1991), Tidal hydrodynamics. John Wiley \& Sons.

23. Valle-Levinson, A., C. Reyes, and R. Sanay, (2003), Effects of bathymetry, friction, and rotation on estuary-ocean exchange. Journal of Physical Oceanography. Vol.33(11): p. 2375-2393.

24. Friedrichs, C.T. and O.S. Madsen, (1992), Nonlinear diffusion of the tidal signal in frictionally dominated embayments. Journal of Geophysical Research: Oceans. Vol.97(C4): p. 5637-5650.

25. Walters, R.A. and F.E. Werner, (1991), Nonlinear generation of overtides, compound tides, and residuals. Tidal hydrodynamics: p. 297-320.

26. Valle-Levinson, A. and K.M. Lwiza, (1997), Bathymetric influences on the lower Chesapeake Bay hydrography. Journal of Marine Systems, Vol.12(1): p. 221-236.

27. Valle-Levinson, A., W.C. Boicourt, and M.R. Roman, (2003), On the linkages among density, flow, and bathymetry gradients at the entrance to the Chesapeake Bay. Estuaries, Vol.26(6): p. 1437-1449. 